\title{
NEO-DESARROLLISMO Y NUEVO REGIONALISMO EN FORMOSA (NORDESTE-ARGENTINO): OPERACIONES ESTATALES Y REELABORACIÓN NEOLIBERAL
}

\author{
Ernesto Fabián Giuliano* \\ *Universidad Nacional de Formosa, Facultad de Administración Economía y Negocios, Formosa, Argentina
}

\begin{abstract}
Resumen
Entre 2003 y 2015, el Estado argentino impulsó una modalidad de crecimiento económico bajo parámetros "neo-desarrollistas". En este marco, en la provincia de Formosa se implementaron políticas públicas que, guiadas por las ideas del "nuevo regionalismo", institucionalizaron una configuración territorial de procesos de re-escalonamiento/territorialización y de dispositivos fragmentarios de gobernanza. El propósito del presente artículo es analizar cómo operan y se dinamizan tales ideas en este ámbito subnacional. Para ello, se indagan tres dimensiones: el contexto y las formas institucionales; los procesos de re-escalonamiento/territorialización y los dispositivos institucionales fragmentarios de gobernanza. Se concluye que la acción del Estado introduce una lógica de co-producción de políticas con los actores regionales/locales público-privados, que, además de imponer un despliegue de procesos de mercantilización de la naturaleza, conlleva una implicación estatal facilitadora y renovadora de procesos de desarticulación fragmentante, continuando y re-elaborando el proyecto neoliberal.
\end{abstract}

Palabras clave

Neodesarrollismo; Nuevo regionalismo; Neoliberalismo. 


\title{
NEO-DEVELOPMENTALISM AND NEW REGIONALISM IN FORMOSA (NORTHEAST-ARGENTINA): STATE OPERATIONS AND NEOLIBERAL REWORKING
}

\author{
Ernesto Fabián Giuliano* \\ *Universidad Nacional de Formosa, Facultad de Administración Economía y Negocios, Formosa, Argentina
}

\begin{abstract}
Between 2003 and 2015, the Argentine State promoted a mode of economic growth under "neo-developmental" parameters. Within this framework, in the province of Formosa public policies were implemented that, guided by the ideas of the "new regionalism", institutionalized a territorial configuration of re-staggering/territorialization processes and fragmentary governance arrangements. The purpose of this article is to analyze how such ideas operate and become more dynamic in this sub-national sphere. For this, three dimensions are investigated: the context and institutional forms; the re-staggering/ territorialization processes and the fragmentary institutional mechanisms of governance. It is concluded that the action of the State introduces a logic of co-production of policies with the regionallocal public-private actors, which, in addition to imposing a deployment of processes of commodification of nature, entails a facilitating and renewing state involvement of processes. of fragmentary disarticulation, continuing and re-elaborating the neoliberal project.
\end{abstract}

Keywords

Neo-developmentalism; New regionalism; Neo-liberalism. 


\title{
NEO-DESENVOLVIMENTISMO E NOVO REGIONALISMO EM FORMOSA (NORDESTE-ARGENTINA): OPERAÇÕES DO ESTADO E REFORMULAÇÃO NEOLIBERAL
}

\author{
Ernesto Fabián Giuliano* \\ *Universidad Nacional de Formosa, Facultad de Administración Economía y Negocios, Formosa, Argentina
}

\begin{abstract}
Resumo
Entre 2003 e 2015, o Estado argentino promoveu um modo de crescimento econômico sob parâmetros "neodesenvolvimentistas". Nesse quadro, foram implementadas políticas públicas na província de Formosa que, orientadas pelas ideias do "novo regionalismo", institucionalizaram uma configuração territorial de processos de re-escalonamento/territorialização e arranjos de governança fragmentados. O objetivo deste artigo é analisar como tais ideias operam e se tornam mais dinâmicas nesta esfera subnacional. Para isso, três dimensões são investigadas: o contexto e as formas institucionais; os processos de re-escalonamento/territorialização e os fragmentários mecanismos institucionais de governança. Conclui-se que a ação do Estado introduz uma lógica de coprodução de políticas com os atores público-privados regionais/ locais, o que, além de impor um desdobramento de processos de mercantilização da natureza, implica um envolvimento estatal facilitador e renovador. de processos de desarticulação fragmentária, continuando e reelaborando o projeto neoliberal.

Palavras-chave

Neo-desenvolvimentista; Novo regionalismo; Neoliberalismo.
\end{abstract}




\title{
NEO-DESARROLLISMO Y NUEVO REGIONALISMO EN FORMOSA (NORDESTE-ARGENTINO): OPERACIONES ESTATALES Y REELABORACIÓN NEOLIBERAL
}

\author{
Ernesto Fabián Giuliano
}

\section{Introducción}

El trabajo transita entre los años 2003 y 2015. Se trata de un espacio temporal, caracterizado por Algranati, Seoane y Taddei (2011) como de "neo-desarrollismo" para el grupo de países encabezados por Brasil y Argentina'. En esas naciones, se procura durante este período recobrar

\begin{abstract}
su aspiración a reconstruir la autoridad estatal y su papel en el sostenimiento de ciertas actividades industriales, la búsqueda de una mejor inserción internacional en el marco de la mundialización capitalista y la restitución del monopolio de la política al Estado y las mediaciones partidarias, asegurando las bases de su legitimidad en cierta recuperación del empleo y con una serie de políticas sociales compensatorias de carácter masivo (ALGRANATI; SEOANE; TADDEI, 2011, p. 30)
\end{abstract}

A través de estos lineamientos, en la Argentina se intenta dar respuestas superadoras al proceso neoliberal desencadenado desde mediado de los años '70 y que se consolida luego en la década de los '9o, siendo el momento culmine, la crisis del año 2001. Sin embargo, y a pesar de esa nueva impronta que busca la

1. Las experiencias de Bolivia, Ecuador y Venezuela parecen adquirir, en este tiempo, un mote más radical asociado al socialismo del siglo XXI y el buen vivir (KATZ, 2013). KATZ, C. Anatomía del kirchnerismo. Rebelión. 2013. Disponible en: https://fisyp.org.ar/wp-content/uploads/media/uploads/anatomia. pdf Acceso en: 25 de septiembre de 2020. 
reconstrucción del Estado y su autoridad, esta no logra desterrar de raíz el proceso extendido del proyecto neoliberal, que va imponiéndose en la práctica, a través de las ideas del nuevo regionalismo (NR) o como señala Brandão (2007, p. 36), el "pensamiento único localista”. Esas ideas, configuran un conjunto de discursos, propuestas académicas y casos testigos, que penetran los territorios y se traducen en políticas públicas, a través de la aceptación acrítica de la elite dirigencial y los ejecutores de política que accionan este conjunto de ideas, en las regiones y localidades.

En estos nuevos escenarios, situamos a Formosa como provincia del Nordeste argentino e integrante de las jurisdicciones provinciales de la "periferia rezagada" (CAO; VACA, 2006, p. 109). Se caracteriza por producir bienes provenientes de las actividades intensivas en recursos naturales, posee un acentuado proceso de tercerización (GIULIANO, 2015), escasa industrialización y dependencia con la región central del país, siendo su vinculación "subordinada dentro de la matriz productiva nacional trazada a partir de grandes empresas nacionales y extranjeras" (SCHORR; FERREIRA; GORESTEIN, 2012, p. 55). Estos elementos son los que vehiculizan las lógicas de producción y circulación de bienes, asociadas al "nuevo ciclo de reprimarización” (GORENSTEIN, 2012, p. 37).

En esas tramas complejas, surge preguntarnos: ¿Cómo operan y se dinamizan en territorios periféricos como el de Formosa, las ideas del NR? ¿Qué procesos de re-escalonamientos/territorialización y dispositivos fragmentarios de gobernanza se despliegan en el territorio como expresión de los mecanismos que se abigarran, en las decisiones de política, dándole continuidad y reelaboración al proyecto neoliberal?

Para contestar estos interrogantes, el artículo se organiza en dos apartados principales. En el primero, se aborda el proceso contextual que fue configurando a las ideas del NR hasta convertirse luego, en una plataforma común denominada "nueva ortodoxia regionalista” (NOR), (FERNÁNDEZ; AMÍN; VIGIL, 2008) en convergencia con los planteos de Brandão (2007) y que logra su inserción en la periferia, a través de la dinamización de las políticas públicas. En el segundo, se pone atención a cómo se operacionaliza el NR en la provincia de Formosa. Se analizan para ello, los procesos de re-escalonamientos/territorialización y los dispositivos fragmentarios de gobernanza que proliferan y se expanden en el territorio a través de las estrategias neo-desarrollistas y en dicha dinámica, se expone el caso de la localidad de Herradura, como manifestación de esos procesos y dispositivos mencionados y que dan cuenta de los elementos de continuidad y reelaboración del proyecto neoliberal. Por último, se presentan las conclusiones. 
El material empírico que sostiene los argumentos vertidos sigue una metodología de tipo cualitativa que se combina con algunos elementos cuantitativos y cartográficos. El estudio utiliza distintas fuentes como: documentos y datos estadísticos de los organismos oficiales provinciales y nacionales, normas legales, además de entrevistas a informantes calificados asentados en la localidad del caso estudiado, pertenecientes a la actividad turística.

\section{El proceso contextual y las formas Institucionales \\ Transformación capitalista, configuración del nuevo regionalismo y dinámica neoliberal}

Hacia mediado de los años 70 del siglo pasado se agotó la era fordista del capitalismo. Desde entonces un proceso multidimensional de cambio social recorre el planeta, sacudiendo la organización económica y las formaciones políticas, y junto a ello también los arreglos sociales y los repertorios culturales. Habitan el núcleo de estas transformaciones económicas la internacionalización del comercio, las inversiones y las finanzas, concurrentemente con la especialización flexible y la descentralización de la producción. Se trata de un nuevo paradigma, al que Lipietz (1994, p. 29) denomina el "modelo de desarrollo posfordista".

En conjunto, tales mutaciones afectaron poderosamente las formas de regulación económica por parte del Estado y redefinieron el acoplamiento estructural de lo económico y lo político. Particularmente, minaron a la economía nacional como objeto de gestión estatal. Los Estados nacionales, así, se convirtieron en dominios fracturados de autoridad política, asediados por las presiones sobre sus funciones, jurisdicciones y capacidades.

El debilitamiento del ámbito nacional como esfera prioritaria de la organización económica es el resultado de un triple movimiento (JESSOP, 2008): la transferencia de algunas de las capacidades y funciones del Estado nacional a cuerpos internacionales; la delegación de otras a niveles locales dentro del Estado nacional; y la usurpación de otras aún por parte de redes emergentes horizontales (locales y regionales) que pasan de largo los Estados centrales y conectan las localidades y las regiones en naciones diversas. El desmantelamiento del capitalismo organizado de posguerra, centrado en el Estado nacional y su rol marcadamente intervencionista, desató, de la mano de la reestructuración económica, una reconfiguración de las escalas políticas, ganando prominencia los niveles subnacionales y globales.

Acompañando estas transformaciones de la articulación política-economía en el núcleo del sistema capitalista, tanto en la literatura académica como en los discursos técnicos y de los formuladores de política comienza a considerarse a la escala regional como la unidad fundamental de la vida social del capitalismo contemporáneo y núcleo central de coordinación de las formas más avanzadas de la 
vida económica. En consecuencia, comienza a concebírsela como un nivel privilegiado en el diseño de políticas.

Un estímulo particular al sazonado de la mirada regionalista fue la percepción de que entre 1970 y 1980 algunas regiones en las economías capitalistas desarrolladas crecían más rápido que los núcleos industriales establecidos dentro de esos mismos países. Se observaba también que, en estas nuevas comarcas dinámicas y de proximidad 2 , a las que se comenzó a llamar "distritos industriales" (BECATTINI, 1992), prevalecían pequeñas empresas, empapadas de un vago espíritu local emprendedorista. Esto contradecía las teorías y políticas dominantes en ese momento basadas en grandes proyectos de infraestructura, grandes inversiones industriales y una fuerte guía/asistencia del Estado. Muy pronto tales regiones, sus pequeñas firmas y su estructura social se convirtieron en los símbolos del éxito del capitalismo a pequeña escala, desde abajo, con su carácter altamente competitivo y empresarial/emprendedorista. Pasaron a ser así un modelo para emular y mejorar.

Así desde el enfoque evolucionista-institucionalista ${ }^{3}$ se aportan los estudios sobre los "milieux innovateurs", su evolución a los "sistemas regionales de innovación” con Cooke (1992, p. 365) y la configuración de “clúster” propuesta por Porter (1998, p. 78). Todas ellas comulgan en sostener los ascensos de los espacios global-locales o regionales como núcleos estratégicos y desencadenantes de procesos de industrialización y desarrollo.

Esta lectura se volcó a las políticas de los Estados europeos en la década de los ‘90, convirtiéndose en la piedra angular del llamado NR. Muy rápidamente, sus abogados la transformaron en ortodoxia, amalgamando procesos y áreas en una sola categoría, promoviéndola como el prototipo de una nueva era global de acumulación y crecimiento (AMIN; ROBINS, 1990; HADJIMICHALIS, 2011).

De ese proceso complejo y diverso de voces, Fernández, Amín y Vigil (2008, p. 12-14) fundamentan la emergencia de la NOR como las bases teóricas adoptadas y replicadas en el campo de las políticas públicas de manera acrítica durante las últimas dos décadas en el Sur Global y su acople en comulgar con esas bases, el ascenso de los espacios subnacionales como los núcleos estratégicos de acumulación

2. Amin (1998, p.77) explica que en la visión institucionalista la proximidad comprende los parámetros sociales e institucionales para la acción económica, tales como: el poder de las lógicas y tradiciones de comportamientos locales; las propiedades de las redes de contacto cara a cara; la calidad de las instituciones locales, las normas sociales y las convenciones. AMIN, S. El capitalismo en la era de la globalización. Barcelona: Paidós, 1998.

3. Ambos cuerpos de pensamiento, expresó Amin (1998, p.71), destacan la idea de que la vida económica es un proceso instituido y una actividad socialmente enraizada y, por lo tanto, su evolución está sujeta a un contexto específico y una trayectoria histórica. 
y crecimiento, vía el fomento de la competitividad, y su inserción a los circuitos globales de actividad económica.

Esa emergente configuración, como se podrá apreciar en esta parte del trabajo y en el próximo apartado, representa una reelaboración del proyecto neolibe$\mathrm{ral}^{4}$, que introduce en la práctica, una lógica de coproducción de políticas con los actores regionales público-privados, que imponen una extensión de los procesos de mercantilización, a través de una implicación estatal que facilita un renovado y más complejo proceso de desarticulación fragmentante al momento de accionar la dinámica regional.

Veamos, durante el cenit neoliberal que se imponía rigurosamente en América Latina; Argentina, profundiza el proceso de reformas estructurales delineadas por el Consenso de Washington y su armonía tirana de mercado. ${ }^{5}$ Como paquete económico sustentado ideológicamente con la economía neoclásica, ese programa comprendía procesos de privatizaciones, desregulación, liberalización y descentralización administrativa.

La consolidación del neoliberalismo redefinió profundamente la relación entre Estado y mercado en Argentina, dándole cierre definitivo al modelo de desarrollo vigente desde la década de 1930, y reestructurando regresivamente las relaciones entre capital y trabajo. Así, la ofensiva neoliberal de los 90 desguazó el Estado populista-interventor asociado al modelo de desarrollo basado en la industrialización por sustitución de importaciones en una economía semicerrada, con redistribución progresiva del ingreso y con políticas activas de intervención estatal en la economía. Emergió en su reemplazo un modelo de desarrollo aperturista basado en la producción y exportación de productos básicos de escaso valor agregado, con un mercado interno reducido, acoplado a una forma de Estado neoliberal o neoconservadora. Como parte de esta mudanza, la modalidad periférica y sui generis del Estado de Bienestar adoptado por el Estado argentino desde los 1940

4. Se trata de un proyecto de clases representada no solo por las fracciones del capital transnacionalizado que rompen barreras nacionales y adquieren capacidad de operar multi-localizadamente a escala global, sino también, por una amalgama de actores institucionales que entronizan operativamente esas fracciones y se proyectan como clase transnacional, propagando hegemónicamente un complejo ideológico -de organizaciones, relatos, prognosis, prácticas- que resalta las virtudes de sumarse a facilitar la expansión de la marketization, encontrando una aceptación/consensualidad en diversas fracciones del capital no transnacionalizado. (FERNÁNDEZ, 2016, p. 28)

5. La arquitectura de esas reformas se apoyó en tres leyes fundamentales: 1) la Ley de Reforma del Estado ( $\mathrm{N}^{\circ}$ 23.696), 2) la Ley de Emergencia Económica ( $\mathrm{N}^{\circ}$ 23.697) y 3) la Ley de convertibilidad $\left(\mathrm{N}^{\circ}\right.$ 23.398) que estableció, entre otros aspectos, un tipo de cambio fijo con caja de conversión a la tasa de un peso por un dólar. 
también fue socavada y reemplazada, para atender a las profundas consecuencias sociales de todo el proceso de ajuste, por formas cercanas al "trabajismo". ${ }^{6}$

Dicho modelo, tuvo un impacto devastador mayúsculo en los espacios subnacionales periféricos y empobrecidos como Formosa. Las políticas de desregulación y privatización de entes públicos, así como de apertura comercial indiscriminada, desarmaron la armadura que permitía la reproducción de las pequeñas y medianas explotaciones agropecuarias, sostén de la economía provincial en la etapa “desarrollista” (MANZANAL, 2000; CETRÁNGOLO; GATTO, 2003). De esta suerte, la provincia sufrió uno de los procesos más severos de reducción de las actividades productivas (CETRÁNGOLO; GATTO, 2003). Sumado a eso, la transferencia de funciones y decisiones concentradas hasta ese entonces en el Estado nacional hacia el Estado provincial, sin ser acompañada por los recursos adecuados, potenció las consecuencias deletéreas sobre las condiciones socioeconómicas de la jurisdicción.

Las prescripciones de la NOR, aparecen precisamente en este momento álgido de la terapia de shock neoliberal hacia mediado de los años 9o, para alentar la regeneración de las "economías regionales” argentinas y como marco orientador de la política pública del endeble Estado provincial formoseño. En esta coyuntura lo hace fundamentalmente a través de las intervenciones diseñadas para expandir el dominio del capital en las comarcas más aisladas del territorio provincial: el extremo Oeste. Por un lado, con el proyecto de desarrollo para el Centro-Oeste, un ambicioso plan de infraestructura y diseño de legislación, emprendido por el Estado provincial, orientado a atraer a la inversión extranjera ligada a los agronegocios. A este emprendimiento, y adaptando la noción de "anclaje espacio-temporal" de Harvey (2005), Giuliano (2015, p.147) lo califica como Anclaje Espacial del CentroOeste. Por otro lado, con el Bosque Modelo Formoseño, una asociación voluntaria de personas interesadas en el desarrollo forestal sustentable local creada a fines de la década de 1998 bajo el patrocinio del Estado nacional y anclada en la lógica de la descentralización y las nuevas formas de gobernanza neoliberal de partenariado público-privado.

Gestionando entusiastamente este proceso neoliberalizador a escala subnacional, la elite administradora del Estado provincial pergeña en esa década un discurso performativo sobre el modelo formoseño para el desarrollo provincial MFDP que, con el tiempo confluye y se retroalimenta con los insumos importados

6. Jessop (2008, p. 316) sintetiza la idea clave del "trabajismo" (workfarism) diciendo que se trata de "una reorientación general de la política social desde la visión redistributiva basada en la extensión de derechos sociales en un Estado nacional hacia un tipo de enfoque más productivista y dirigido al ahorro de costes en una economía abierta”. 
de la NOR.7 El mentado modelo, basado en la postulación de una identidad sustentada en una cultura pública homogénea formoseña -que aseguraría una disposición hacia la confianza mutua entre otros rasgos de comportamiento-, se plantea como una configuración, alentada por el Estado provincial, de un ambiente de negocios en donde confluyan actores diversos que puedan movilizar endógenamente los recursos existentes con vistas a aprovechar las oportunidades del mercado global. De este modo se iban sentando las bases para el despliegue pleno de intervenciones de desarrollo local y regional, en el marco del regionalismo empresarial, en la década siguiente.

La caída catastrófica del sumun neoliberal en Argentina a fines de 2001, en medio de una profunda crisis política, económica y social, da una vuelta de tuerca a este curso neoliberalizador. La salida de este crac tuvo como punto de arranque el abandono abrupto de la convertibilidad a través de una megadevaluación y, desde entonces, un viraje hacia una revalorización de la intervención estatal para orientar el desarrollo económico capitalista, moderando el brutal disciplinamiento del mercado de los 90. ${ }^{8}$ Asimismo, también comienza a delinearse un rol más activo del Estado como agente de redistribución en vistas a mitigar las deletéreas consecuencias sociales de la trayectoria económica del país. Esta orientación se profundiza en 2003 con la asunción del presidente Néstor Kirchner. Queda delineado así, y hasta 2015, un modelo que, dentro de las experiencias posneoliberales de tonalidad progresista que se practican en Sudamérica -mencionadas al inicio de este artículo-ha sido calificado, desde distintas vertientes, de "neo-desarrollista" (FERNÁNDEZ, 2016; FÉLIZ, 2019).

Para Giuliano (2019, p.175) durante el transcurso de este período caracterizado por profundos cambios, Formosa estará signado por tres rasgos institucionales fundamentales: 1) las modificaciones sucesivas en dos oportunidades de la Carta Magna de la provincia -1991 y luego en $2003^{9}$-; 2) la continuidad hegemónica del partido-Estado ${ }^{10}$ en la dirección funcional, política y administrativa del Estado y

7. Dicho discurso se esgrime en los Preámbulos de las Reformas Constitucionales de los años 1991 y 2003,
que hacen referencia a la voluntad de "plasmar el modelo formoseño para un proyecto provincial”.

8. El 7 de enero de 2002 se promulgó la Ley $N^{\circ} 25.561$ (de Emergencia Pública y de Reforma del Régimen Cambiario) que dispuso los cuatro pilares de salida de la crisis: la devaluación de la moneda argentina, la licuación de deudas mediante su pesificación, la instauración de retenciones a la exportación y el congelamiento de las tarifas de servicios públicos (que se habían privatizado la década anterior).

9. En dicha reforma, se impone la reelección ilimitada para todos los cargos electivos y con ello, Gildo Insfrán que fuera electo en 1995 y reelecto en 1999 como gobernador, continúa ejerciendo dicho cargo de manera ininterrumpida trasvasando los 25 años en el Poder Ejecutivo.

10. La hegemonía partido-Estado se asimila al concepto de bloque de poder de POULANTZA (2007). Su continuidad histórica y política es sostenida con la Ley Provincial N 657 o Ley de Lemas del año 1987 
3) a partir de los dos primeros, la implementación dominante del MFDP, de la mano del discurso aludido precedentemente.

Este escenario institucional, a su vez, fue crucial para la construcción de una arquitectura de leyes y arreglos escalares verticalizantes que facultarán con amplios poderes al Poder Ejecutivo Provincial -PEP para decidir sobre el patrimonio del Estado. ${ }^{11}$ Junto a este plexo normativo, se prorrogan las Leyes de Emergencia Económica $\mathrm{N}^{\circ} 1.296$ y 1.342 que se habían puesto en vigencia desde 1991, las que tendrán una continuidad sistemática a través la sanción de las leyes nacionales y provinciales que la prorrogarán, durante todo el período analítico. ${ }^{12}$

De esta manera, desde la reforma constitucional de 1991 a la de 2003, se logra centralizar el poder en el PEP ${ }^{13}$, se debilitan el Poder Judicial y el Poder Legislativo ${ }^{14}$ con pérdida de protagonismo de este último.

No obstante esta mudanza, que implicó un rol más activo del Estado y en el caso formoseño una configuración institucional con arreglos escalares verticalizantes y hegemónica, no alcanzó al corazón de las transformaciones de los 90, ya que "la salida de la crisis se dio manteniendo la mayoría de las reformas neoliberales, con un aparato productivo modernizado, con condiciones flexibilizadas de contratación y consumo de fuerza de trabajo, apertura comercial y eliminación de regulaciones estatales sobre la actividad privada” (SALVIA, 2019, p. 6o, 68). Por ello, en definitiva, la experiencia "neo-desarrollista” argentina se recorta más como un "momento fenómenico" (PINASSI; ADOUE, 2019, p. 13) interno de un proceso neoliberalizador de más largo aliento, como una reacción -aunque

(que irá incorporando algunas modificaciones). Esta hegemonía construida hace que en Formosa gobierne sin interrupciones, el mismo partido político desde el año 1983 (regreso a la democracia en Argentina). POULANTZAS, N. Poder político y clases sociales en el estado capitalista. Buenos Aires: Siglo XXI, 2007.

11. Se trata de la Ley $\mathrm{N}^{\circ} 1.367$ que adhiere a la Ley Nacional de emergencia económica $\mathrm{N}^{\circ} 25.561$. Con ello, se le otorga al PEP poderes extraordinarios (Art. 10) donde se lo faculta entre otras: "a refinanciar y reprogramar las acreencias de cualquier naturaleza del Estado Provincial que se mantenga con distintos Organismos Oficiales y/o Entidades Autárquicas, Centralizadas, Descentralizadas, y/o persona física o jurídica”.

12. Ello ocurre con Ley Provincial $N^{\circ} 1.576$ que adhiere a la Provincia a la Ley Nacional $N^{\circ} 26.729$ que prorroga la vigencia de su similar $\mathrm{N}^{\circ} 26.204$, prorrogada a su vez por las Leyes $\mathrm{N}^{\circ}: 26.339,26.456$ y 26.563 hasta el 31 de diciembre de 2013, que son las prórrogas de la Ley 25.561. Simultáneamente, en Formosa se prorrogan las Leyes Provinciales $N^{\circ}$ : 1296, 1342, 1472, 1367, 1485, 1503, 1518, 1530 y 1544, manteniéndose el “estado de emergencia pública” durante el término establecido en la mencionada Ley Nacional.

13. Véase los Artículos $N^{\circ} 62$ y 65, de la Constitución Provincial. Honorable Cámara de Diputados de la Provincia de Formosa (2003a, p.12). Constitución de la Provincia de Formosa del año 2003. Disponible en: https://www.legislaturaformosa.gov.ar/biblioteca. Acceso en: 20 de Abril de 2015

14. Véanse el Artículo 120 Incisos 4 y 5 y El Artículo 170 Inciso 6. Honorable Cámara de Diputados de la Provincia de Formosa (2003b, p.25-36). Constitución de la Provincia de Formosa del año 2003. Disponible en: https://www.legislaturaformosa.gov.ar/biblioteca. Acceso en 20 de Abril de 2015. 
no antagónica- (FERNÁNDEZ; CARDOZO, 2012, p. 16) ante los efectos disolventes del momento anterior.

Así, si bien a partir de 2002/03 se puede observar "un nuevo protagonismo del Estado Nacional en la economía” y, específicamente, en "la dinámica económica y territorial” (ADRIANI, 2016), esto no significa que se haya desdibujado sustancialmente la lógica neoliberalizadora. García (2016, p. 190) desde una postura amigable hacia la gestión neo-desarrollista, apunta en este sentido que, si bien hubo un "avance elocuente" en los instrumentos de política pública de los que dispuso el Estado nacional en relación a la problemática regional, "la tradicional función facilitadora del Estado, que actúa como jardinero, no se ha modificado aún”. Fernández y Comba (2017, p. 378), desde una postura más crítica, rematan con mayor precisión: "las políticas neoliberales... continuaron casi sin alteraciones (o con pequeños ajustes incrementales) en un escenario de (re) industrialización sustitutiva de importaciones o neodesarrollista”.

Esta dinámica procesual, que evidencia entre los años 90 y el ciclo neo-desarrollista la continuidad reelaborada de un neoliberalismo más complejo en su funcionamiento, es producto de la estructuración de un amplio soporte superestructural y supranacional de engranajes que le ha permitido al proyecto neoliberal, acelerar - en los años 9o - y abigarrar -en años neo-desarrollistas- su desenvolvimiento en el entramado estatal/territorial. Esos engranajes cimientan su articulación a través de las redes económicas globales - REG y las redes de políticas globales - REP (FERNANDEZ, 2016, p. 28-29). ${ }^{15}$

Esa articulación complementaria en redes, le ha permitido al neoliberalismo, expandirse a escala global, como proceso hegemónico (PECK, 2012, p. 7-27) pero al mismo tiempo, incompleto y re-emergente como proyecto, ya que presiona siempre en dirección a la marquetización sin llegar nunca a destino, es decir, opera como una marquetización infinit que genera nuevas formas de mercantilización y de subordinación .Es discrepante, debido a que no existe un experimento puro que lo exprese como tal, en consecuencia, transita como un paradigma mixto, abigarrado y cambiante de reestructuración escalar del Estado cuyo núcleo reside en: "la movilización del poder estatal para extender el dominio del mercado" (PECK; TICKELL, 2003, p. 166).

15. Las REG están constituidas y controladas por empresas transnacionales, con la capacidad de seleccionar ámbitos regionales y nacionales, interactuando en tiempo real con una multiplicidad de actores institucionales y económicos en dichos ámbitos. Esas redes, se han configurado -de manera retroalimentaría- a través de un complejo regulatorio trasnacional que involucra a organizaciones supranacionales -sostenidas por “Estados nacionales fuertes, y dominantes”-, de los países centrales -que actúan también en la forma de RPG. 
Esa movilización del poder estatal en la que se mimetiza y extiende el dominio del mercado, originó un "patrón general”, de "glocalización” (SWYNGEDOUW, 2010, p. 62) que se desarrolla a través de los procesos de re-escalonamientos y territorialización. ${ }^{16}$ El primero explica Peck (2010, p. 91): "genera la recombinación, reorganización y reconstitución de funciones y de relaciones escalares, en lo institucional, y regulativo"; para Swyngedouw (2010 p. 56-57) el segundo: "produce una configuración socio-espacial disputada. Constituyendo la arena donde se liberan las batallas por el control y el empoderamiento del espacio social”.

Ahora bien, es importante destacar, que este amplio soporte superestructural y supranacional a través de la cual ha sedimentado la NOR, ha sido acompañado por una activa aceptación de sus elementos constitutivos por parte de los programas nacionales y regionales vinculados al desarrollo empresarial y regional/ local, ${ }^{17}$ que comenzaron a instalarse en la Argentina, en la que Formosa no fue la excepción.

En el caso de Argentina, resultan de importancia el programa de PNUD sobre complejos productivos financiados por el Estado Nacional a través de la Secretaría de la Pequeña y Mediana empresa (SEPYME), así también ha jugado un papel clave en la promoción con vinculación tecnológica el Fondo Tecnológica Argentino (FONTAR).

Al respecto, el ingreso e institucionalización de la NOR en Formosa y sus localidades, inició sus primeras experiencias de re-escalonamiento y territorialización hacia mediados y fines de los '9o como hemos anticipado, con dispositivos fragmentarios como el proyecto del desarrollo del Centro-Oeste y la propuesta del Bosque Modelo Formoseño.

En línea con las ideas de la NOR, desde el año 2004 se implementa en Argentina El Plan Estratégico Territorial (PET), coordinado a través de la Subsecretaría de Planificación Territorial de la Inversión Pública, por el Ministerio de Planificación Federal Inversión y Servicios Públicos. ${ }^{18}$ Según los documentos oficiales, el PET

\footnotetext{
16. La reterritorialización y la desterritorialización, son las transformaciones del espacio en sentido expansivo o contractivo respectivamente, derivados de las dinámicas escalares en tanto conflictos de poder, entre los distintos grupos sociales y sus estrategias de cooperación y competencia, haciendo surgir configuraciones con escalas nuevas que delimitan nuevas fronteras.

17. Se estima en Fernández (2008, p. 49) que en solo tres países (Brasil, Chile, México) se habían aplicado hacia 2005 más de 650 proyectos que proponían alguna forma de articulación productiva con asociación público-privada a nivel territorial (CEPAL, 2005). En el caso brasilero se destacan entre todas estas iniciativas programas como el Arrenjos Productivos impulsado desde el Servicio Brasilero de Apoyo a la Pequeña y mediana Empresa (SEBRAE). Disponible en: http://www.sebrae.com.br.
}

18. Desde el año 2015 la subsecretaría funciona en el ámbito del Ministerio del Interior, Obras Públicas y Vivienda. Disponible en: http://www.planificacion.gob.ar/contenidos/2605. 
se propone construir un marco de referencia que ayude a orientar las políticas públicas, con la participación asociada de los niveles subnacionales del Estado y la "sociedad civil". La orientación más general habla de construir un "plan general de desarrollo equilibrado y equitativo" de los territorios provinciales, mediante la intervención en la composición territorial del país, en el rescate de capacidades "locales", la mejora del desarrollo de redes urbanas, incrementar y racionalizar las dotaciones de infraestructura, y el trabajo general sobre las zonas más rezagadas poniendo en valor sus propios recursos humanos y naturales. Vinculada a esta manera de entender "el desarrollo territorial de nivel provincial y local", comienzan a desarrollarse paralelamente los PEDL. En este caso, es el Consejo Federal de Inversiones (CFI), a través de su Línea de Trabajo sobre Planificación Estratégica Regional, la institución del Estado nacional que asiste y acompaña las experiencias en los municipios (y las provincias) interesados. ${ }^{19}$ Cabe agregar que la programación, la ejecución y las determinaciones de estos planes son competencia de las jurisdicciones provinciales y municipales. A su vez, ello ha implicado en el surgimiento de espacios institucionales creados por la provincia, que operan en las escalas regional/local del territorio a través de los Programas de competitividad ${ }^{20}$, la Agencia de Desarrollo Empresarial (ADE) ${ }^{21}$, iniciaciones de clúster $^{22}$ contenidas en el Ministerio del Interior, Planes-Provincia. Plan Estratégico Territorial Formosa 2015: El Plan de inversiones que conduce la visión de provincia en el largo plazo (2008). ${ }^{23}$

En esta visualización escalar y de dispositivos institucionales fragmentarios se destacan dos líneas de intervención estatal sobre la cuestión regional en esta etapa: el Plan Estratégico Territorial (PET) y los Planes Estratégicos de Desarrollo Local

19. El CFI es un organismo de las provincias argentinas creado en el año 1959, esto es, en plena vigencia del Estado desarrollista, mediante un Pacto Federal. Su misión es promover el desarrollo armónico e integral del país sobre la base de un esquema solidario y descentralizado. Para ello, utiliza dos grandes herramientas: la cooperación técnica y la asistencia financiera. La entidad acompañó el financiamiento de los procesos de Planes Estratégicos de Desarrollo Local en el territorio de Formosa. Disponible en: http://cfi.org.ar/accionar/lineas-de-trabajo/planificacion-estrategica-regional.

20. Operan el territorio sin conexión sistémica con los PEDL: a) Formación de Clúster en el Sector Privado, b) Programa de Competitividad del Norte Grande-Ministerio de Economía y Finanzas Públicas de la Nación y Financiamiento del Banco Interamericano de Desarrollo (BID); c) Estrategia Provincial para el Sector Agroalimentario (EPSA) elaborado con la asistencia técnica del PROSAP y financiamiento del BID d) Plan de Mejora de Competitividad (PROSAP) Norte Grande, con financiamiento del BID. (MINISTERIO DEL INTERIOR, 2008, p. 90-112). Disponible en: https://www.mininterior.gov.ar/planificacion/pdf/planes-prov/FORMOSA/Plan-Estrategico-Formosa-2015.pdf.

21. La ADE, es una institución sin fines de lucro donde confluyen empresarios, cámaras, universitarios, técnicos y organismos gubernamentales para desarrollar las potencialidades de la economía regional y mejorar la competitividad de las empresas. Disponible en: https://www.adeformosa.org.ar.

22. El Programa de Servicios Agrícolas Provinciales (PROSAP) articula entre sus instrumentos de implicación las Iniciativas de Desarrollo de Cluster (IDC). Disponible en: http://www.prosap.gov.ar.

23. El Plan Estratégico Territorial Formosa 2015, se inició en el año 2005. 
(PEDL), ambas serán abordadas en el segundo apartado de este artículo, poniendo luego foco en las acciones que desencadenan estas políticas cuando se dinamizan en el territorio, facilitando un renovado y más complejo proceso de neoliberalización. Para la visualización de estas acciones exponemos el caso de la localidad de Herradura. $^{24}$

La impronta de las políticas regionalistas/localistas afincadas en el espacio-social formoseño, devela la imagen de un andamiaje de dispositivos fragmentarios de diferentes características y de articulación de objetivos, pero que tienen como principio rector de construcción, su inspiración en las líneas envasadas por el pensamiento único localista de base "participativa” "universales” y "comunitarista".

Se despliega con ello una nueva arquitectura regulatoria, que Peck y Tickell (1994) la denominan neoliberalismo de reconstrucción o "roll out" del proceso neoliberalizador; cuyo origen se encuentra, en la reacción académica heterodoxa que orientó sus argumentos a nuevas formas de construcción de instituciones y de intervención gubernamental, diferente al momento destructivo (“roll-back") de los noventa. ${ }^{25}$

Si bien la arquitectura configurada ya había iniciado su implante en Formosa desde mediados y fines de la década de 1990 como ya hemos aludido. Su proliferación se hace evidente durante el ciclo del neo-desarrollismo. Es esa dinámica proliferada del nuevo regionalismo, y sus acciones de política pública en el territorio formoseño la que revisamos en el siguiente apartado, en la que se pone foco en la regionalización, el PET y los PEDL.

\section{La Irradiación del nuevo regionalismo}

Re-escalonamientos/territorialización y los dispositivos fragmentarios de gobernanza bajo el manto del nuevo regionalismo en Formosa

Con el inicio del ciclo neo-desarrollista comienzan a multiplicarse los dispositivos de políticas fragmentarias en toda el área formoseña. El remodelado de ordenamiento territorial de la provincia a través de un proceso de “regionalización” -la delimitación de nueve regiones a través de diferentes

\footnotetext{
24. Se ha elegido a la localidad de Herradura, porque representa dentro de las fragmentarias experiencias de PEDL diseminados en el territorio formoseño, el único caso donde el plan es predeterminado en función a un eje específico de territorialización: la actividad turística.

25. “[...] la práctica del neoliberalismo tiene poco que ver con la desregulación laissez-faire -dejar a los mercados que hagan su trabajo, Estado ausente-, sino que está asociada a la deconstrucción extensiva y la reconstrucción de instituciones frecuentemente en nombre de o en la imagen de los 'mercados”, (PECK; TICKELL, 2003, p.167-68).
} 
“criterios de homogenización”26 - fungió como el punto de partida de todo el proceso (ver Mapa 1).

\section{Regionalización de Formosa}

Consensuado entre el Ministerio de Desarrollo Humano, Ministerio de Cultura y Educación, Ministerio de Proucción y la Subsecretaria de Planificación de la Inversión

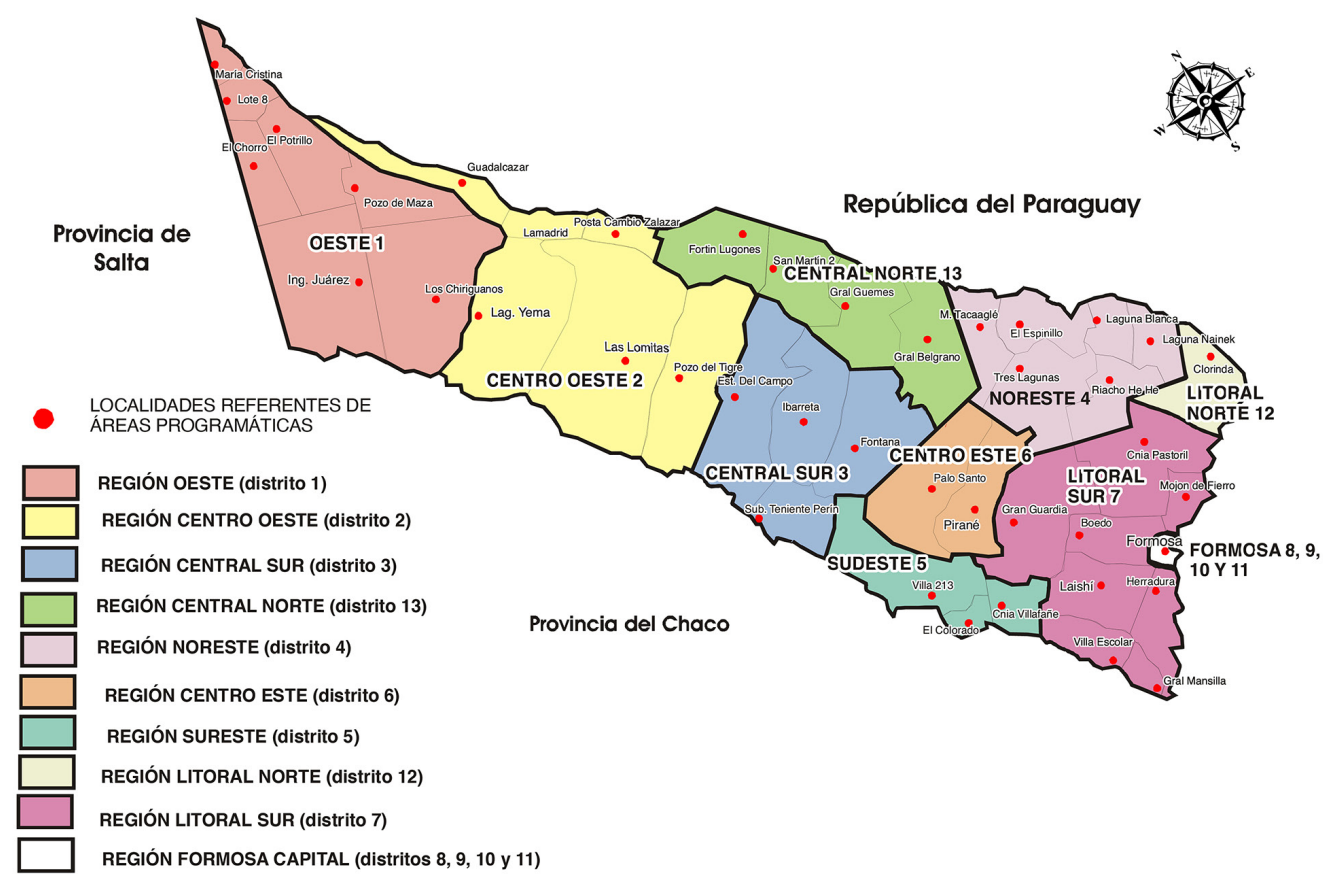

Mapa 1: Regionalización de Formosa

Fuente: elaboración propia en base al mapa de regionalización del Ministerio de Planificación (2006).

Sobre esta base neo-regionalizada comienzan a dinamizarse las ideas del pensamiento localista hacia 2007, con la selección de veinticuatro municipios para poner en marcha los PEDL (ver Mapa 2).

26. Los criterios de homogenización fueron: 1) Marginación: Educación, salud, vivienda, ingreso; 2) Político-Administrativo: Estado y Municipio; 3) Cultural y Étnico: Costumbre, tradiciones, lenguas, raza; 3) Ambientales: Flora, fauna, recursos hídricos; 4) Económicos: Actividades productivas, comerciales, industriales, servicios; 5) Fisiográficos y climáticos: Suelos, temperaturas, orográficos; 6) Infraestructura física: vías y medios de comunicación, canales (MINISTERIO DE PLANIFICACIÓN, 2011, p. 8). Disponible en: https://fsaynea.files.wordpress.com/2011/04/regionalizacion.pdf 


\section{Localidades con Planes Estratégicos de Desarrollo Local}

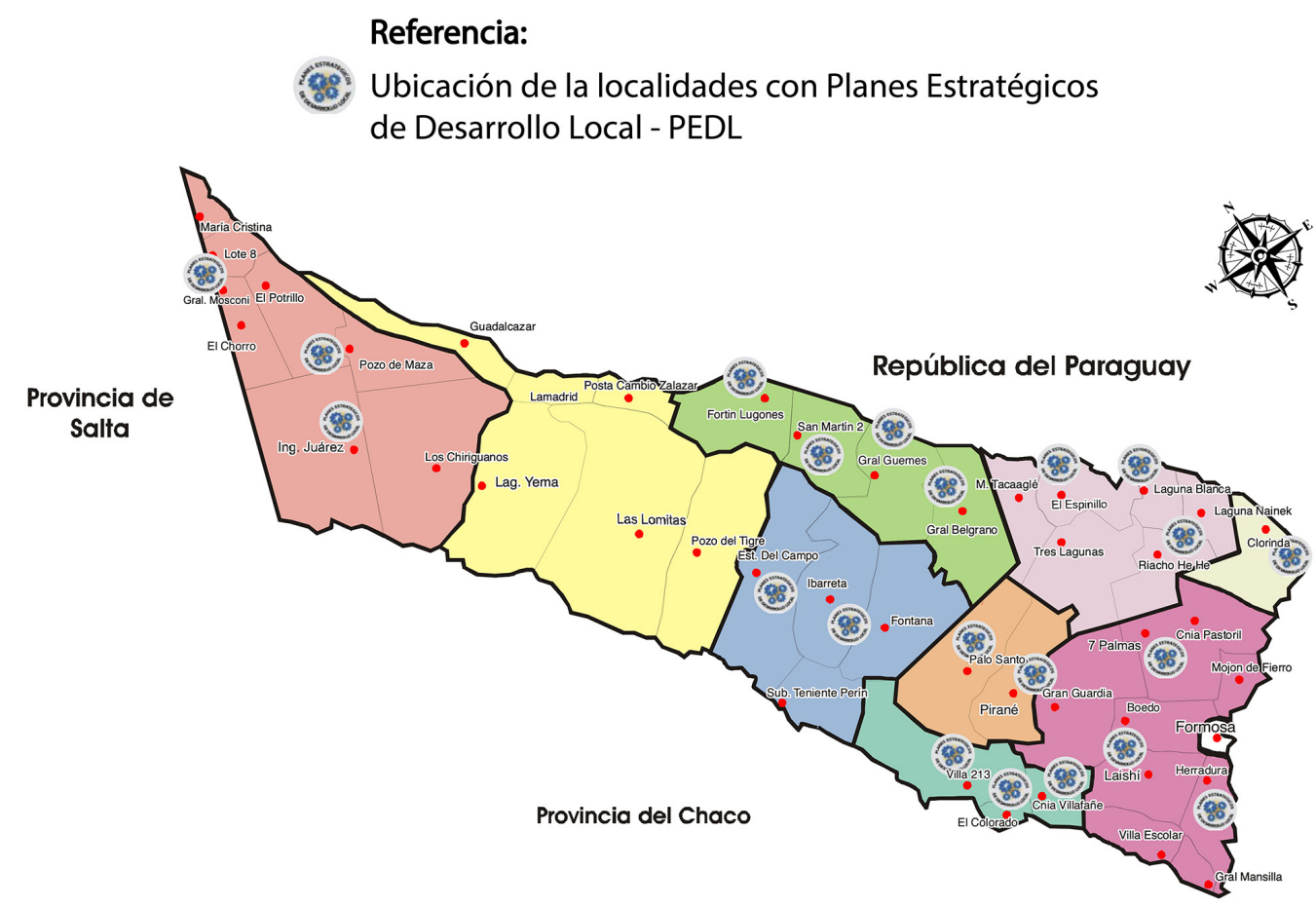

Mapa 2: Localidades de Formosa con PEDL

Fuente: elaboración propia en base al mapa de regionalización del Ministerio de Planificación (2006).

La instrumentación de estos programas se produjo de manera dispareja. Como se puede observar en el Cuadro 1, hacia 2013 había importantes diferencias entre los municipios en cuanto a la fase que transitaba cada uno. ${ }^{27} \mathrm{El}$ escenario regional/local quedó dibujado entonces como un espectro de planificaciones locales fragmentarias, con abordajes de ejes estratégicos diferenciados y desigualmente plasmados según el gobierno local que se trate.

Cabe agregar que esta desigualdad espacial no obedece solo al avance disparejo de los PEDL, sino que sus orígenes remiten al profundo proceso de reescalonamiento del Estado nacional producido en los años noventa.

27. Nos circunscribimos a lo acontecido durante el ciclo neo-desarrollista. Quedan fuera del alcance de este trabajo las fases de la planificación alcanzadas desde 2016. 


\begin{tabular}{|c|c|}
\hline $\begin{array}{l}\text { Fases desarrolladas en los } \\
\text { distintos municipios }\end{array}$ & $\begin{array}{l}\text { Ejes estratégicos del PEDL y año de finalización de los } \\
\text { documentos }\end{array}$ \\
\hline \multicolumn{2}{|l|}{ Fase II } \\
\hline Laguna Blanca & Desarrollo urbano: ordenamiento urbano - plan de ordenamiento urbano \\
\hline Pirané & Desarrollo productivo: cadena de valor por localidad \\
\hline Riacho He Hé & Mayo de 2009. \\
\hline Villa Dos Trece & \\
\hline Clorinda & \\
\hline El Colorado & \\
\hline \multirow{2}{*}{\multicolumn{2}{|c|}{$\begin{array}{l}\text { Ibarreta } \\
\text { Ingeniero Juárez }\end{array}$}} \\
\hline & \\
\hline \multicolumn{2}{|l|}{ Fase III } \\
\hline General Güemes & Desarrollo urbano-ambiental e infraestructura \\
\hline \multirow[t]{3}{*}{ Tres Lagunas } & Desarrollo productivo y cadenas productivas por localidad \\
\hline & Desarrollo comunitario \\
\hline & Mayo de 2010. \\
\hline \multicolumn{2}{|l|}{ Fase IV } \\
\hline General Belgrano & Desarrollo urbano-ambiental e infraestructura \\
\hline Misión Laishí & Desarrollo productivo y cadenas productivas por localidad \\
\hline \multirow[t]{3}{*}{ Villafañe } & Desarrollo comunitario \\
\hline & Género \\
\hline & Diciembre de 2010 \\
\hline \multicolumn{2}{|l|}{ Fase V } \\
\hline Estanislao del Campo & Desarrollo urbano-ambiental: infraestructura urbana- medio ambiente. \\
\hline Palo Santo & Competitividad territorial: cadenas productivas \\
\hline Pozo De Masa & Social: desarrollo comunitario; género, empleo y educación. \\
\hline Buena Vista & Diciembre de 2012 \\
\hline \multicolumn{2}{|l|}{ Laguna Naineck } \\
\hline \multicolumn{2}{|l|}{ Fase VII } \\
\hline San Martín II & Desarrollo urbano: infraestructura urbana-medio ambiente \\
\hline Siete Palmas & Competitividad territorial: cadena de valor por localidad \\
\hline El Espinillo & Social 1: género, cultura y desarrollo comunitario \\
\hline Fortín Lugones & Social 2: educación; empleo y juventud \\
\hline \multirow[t]{2}{*}{ General Mosconi } & $\begin{array}{l}\text { Fortalecimiento ciudadano: construcción de ciudadanía y participación; y, } \\
\text { educación para el consumo }\end{array}$ \\
\hline & Junio de 2013 \\
\hline Municipalidad de Herradura & Áreas estratégicas de intervención \\
\hline \multirow[t]{5}{*}{$\begin{array}{l}\text { Plan Estratégico de Desarrollo } \\
\text { Turístico sustentable de la } \\
\text { microrregión de Herradura y área } \\
\text { de influencia }\end{array}$} & Proyectos prioritarios \\
\hline & Indicadores y Monitoreo de Ejecución del Plan \\
\hline & Indicadores y Monitoreo del Plan \\
\hline & Tendencias en los productos Turísticos \\
\hline & Informe final terminado en diciembre de 2012 \\
\hline
\end{tabular}

\section{Cuadro 1. Datos de los Planes Estratégicos de Desarrollo Local (PEDL)}

Fuente: elaboración propia en base a los los documentos del Ministerio de PlanificaciónPEDL (2010a; 2010b; 2010c; 2010d; 2012a; 2012b; 2013) y del Consejo Federal de Inversiones (2007a; 2007b; 2007c; 2011; 2013b). 
Ambos elementos se complementan de manera dinámica, trasladando procesos, programas y servicios a nivel regional y municipal. Estos últimos asumen esas responsabilidades bajo un esquema de arreglos escalares verticalizantes que se derrama a la escala local, a través de una nueva y abultada agenda de gestión para los gobiernos locales, como se observará.

Por otro lado, jugaron un rol operativo clave las decisiones políticas asumidas por el gobierno provincial, al definir con independencia de la calidad técnica lograda en las elaboraciones de los planes, ${ }^{28}$ avanzar y abarcar con los PEDL al mayor número posible de municipios, intentando con ello como rezan los documentos de los planes, posicionar a la provincia como la de mayor porcentaje de gobiernos locales en utilizar planificaciones estratégicas. Se sumó así Formosa, a la ola de las buenas prácticas impulsadas por los manuales de la NOR.

Se impuso de esta manera, una lógica de re-escalonamientos hacia abajo, que promete empoderar a la sociedad civil y sus actores locales, como dinamizadores del desarrollo aun cuando sus documentos aprobados, reflejen expresiones parciales de la participación de la población lugareña, funcionarios públicos provinciales y locales que plasman en esos documentos, el frenesí por enaltecer ciertas condiciones productivas e identitarias de las cadenas de valor local (existentes o surgidas del plan), que permitan la atracción del capital y el mejoramiento de la competitividad territorial.

Siguiendo esa lógica y como propician los principios de la NOR, la metodología implementada para la elaboración de los PEDL en cada una de las localidades de Formosa, fue homogénea, es decir, se replicaron, idéntica mecánica de trabajo con igual número de momentos, etapas ${ }^{29}$ aunque con alcances diferenciados, según sea la fase de agregación de ejes estratégicos y dimensiones de trabajo incorporados. Todo ello, con independencia de los particularismos sociales, culturales, relaciones de poder económico de diferentes actores, entre otras características de cada territorio local.

Esta división en fases y localidades, que ilustra el Cuadro 1, se operativiza a través del Gobierno de la Provincia y su Ministerio de Planificación, Obras y Servicios Públicos, con la Fundación Arandú (quien coordinó los trabajos en los talleres de los PEDL) y la asistencia del Consejo Federal de Inversiones.

28. En los PEDL Fase III se explicita que, la relevancia de sus documentos se halla en los procesos participativos impulsados por los gobiernos locales, con independencia de su calidad técnica, profundidad o relevancia de la información que contiene (MINISTERIO DE PLANIFICACIÓN, 2010a, p. 87 [PEDL, Fase III]).

29. Se reconocen las siguientes etapas: 1) Organización y Pre-diagnóstico. 2) Diagnóstico. 3) Elaboración del objetivo central y líneas estratégicas. 4) Formulación de los proyectos y propuestas de actuación. 5) Impulso y Seguimiento. 
Con ello, la Fase I y II de los PEDL incluyen solo dos Ejes Temáticos considerados desde la escala regional, como básicos y estratégicos para las localidades: 1) Desarrollo Urbano: Ordenamiento Urbano e Infraestructura y 2) Desarrollo Productivo: Cadenas productivas de valor a desarrollar.

Luego, los municipios Fase III, agregaron a la Fase anterior el Eje Desarrollo Comunitario. En tanto que los alcanzados por la Fase IV, incorporan a los anteriores, el Eje Comunitario y Genero. La Fase V, por su parte, agrega el Eje social subdividida en Eje Social I: dimensiones Género, Cultura y el Desarrollo Comunitario. En tanto que, en el Eje Social II: incluyen las dimensiones Educación, Empleo y Juventud. Por último, la Fase VII es dedicada al informe final del PEDL e integrador de todas Fases anteriores. No obstante, agrega un último Eje al Plan, denominado Fortalecimiento Ciudadano, él que abarca dos dimensiones: Construcción de Ciudadanía y Participación y Educación para el Consumo.

Estos ejes descriptos para cada fase fueron abordados en los planes como líneas de trabajo que no lograron ensamblarse en los documentos publicados de manera sistémica para el abordaje de los problemas detectados. Por el contrario, se esgrime en dichos ejes la perspectiva política de acompasar a la Sociedad Civil y al Estado Local para que por sí mismos generen un espacio fundamentalmente localista. Al respecto, el objetivo de las conclusiones en los documentos PEDL, Fase II, expresan:

Lograr que cada comunidad intervenida, incorpore los componentes básicos de un proceso de planificación estratégica de desarrollo local, buscando detectar y ordenar prioridades que la Sociedad Civil y el Estado, se tracen a sí mismos, en un espacio netamente local, para luego transformarlas en propuestas simples e innovadoras en los ejes temáticos Ordenamiento Urbano e Infraestructura y Cadenas Productivas. (MINISTERIO DE PLANIFICACIÓN, 2007)

Cuando se abordan en la Fase II de los PEDL el Eje Desarrollo Urbano, se hace un detalle de la cartera de obras públicas en cada localidad para atender necesidades de corto, mediano y largo plazo, y en Fases III a VII, se las identifica con las definidas en el PET Formosa 2015 para las localidades alcanzadas. De esta manera, los documentos PEDL actúan como un instrumento legitimador de obras previstas y presupuestadas en el PET, más que como una herramienta de estrategias de desarrollo territorial.

En esa dinámica legitimadora se explicita claramente en los PEDL, que estos surgen como respuesta a los cambios generados a nivel funcional y espacial del Estado, producto de su proceso de reforma, descentralización, la globalización y las crisis en las economías regionales. Al respecto, los documentos expresan esos 
fundamentos en línea con los principios de la NOR desatando los saltos escalares ${ }^{30}$, primero hacia abajo, enunciando la nueva agenda de los Gobiernos Locales:

Tradicionalmente, el rol del gobierno local estaba limitado a la construcción y mantenimiento de la infraestructura (caminos, edificios, plazas, etc.), ejercicio de poder de policía, control administrativo sobre el hábitat y regulación de la seguridad e higiene industrial, control del tránsito, [...] Estas responsabilidades no es que hayan perdido vigencia, sino que ahora la expectativa es mayor.

Se han sumado nuevos campos de intervención a la agenda local debido a procesos de reforma del Estado, el proceso de globalización, crisis de las economías regionales, entre otros factores.

[...] Los nuevos temas que están presentes en la agenda local son: el cuidado del medio ambiente, seguridad ciudadana y protección de los derechos humanos, promoción económica, defensa del consumidor, acceso a la justicia, asistencia a los sectores de pobreza extrema, dentro de los social está el tema de la juventud, de la igualdad de género, prevención de adicciones, salud, vivienda, educación, la administración de políticas sociales y programas de empleo transitorio, asistencia a las micro, pequeña y mediana empresa, apoyo logístico a las fuerzas de seguridad, fomento a la inversión privada en el territorio, preservación del patrimonio cultural y natural, también se debe agregar la demanda interna de la gestión municipal sobre todo en el orden de la capacitación, la búsqueda de permanentes mejoras en la gestión del municipio. (MINISTERIO DE PLANIFICACIÓN, 2012b, p. 37 [PEDL, Fase V])

Luego, en saltos escalares hacia arriba, explicando que:

El desarrollo local propone un cambio de perspectiva, donde la aplicación de la estrategia de desarrollo implica una conciliación entre lo sectorial y lo global que se operativiza a través de redes de intercambios, de conocimientos, de métodos de aprendizaje, de servicios, etc., basadas en la concertación y esta a su vez en el establecimiento de una actitud de confianza y de respeto mutuo. (MINISTERIO DE PLANIFICACIÓN, 2012b, p. 33 [PEDL, Fase V])

En este sentido, para los municipios Fase III, por ejemplo, sin explayar fundamentos al respecto, se proyectan en el Eje Urbano Ambiental la idea de Ecociudad o

30. Los saltos escalares (jumping scales) son definidos por Smith (2003, p.192-212) como las condiciones del poder político y de las reivindicaciones que se expanden de una escala a otra. Siendo las escalas, como los Estados nacional, provincia o municipio, expresiones mismas de la organización de los procesos sociales. SMITH, N. Scale Bending. En: SHEPPARD, E.; MC MASTER, R. (eds.). Scale y Geographic Inquiry: Nature, Society and Method. Londres: Blackwell, 2003. p. 192-212. 
Ciudad Sostenible, acoplándose a las recomendaciones estratégicas europeas escritas en el Libro Verde de Medio Ambiente Urbano (REDE DE REDES DE DESARROLLO LOCAL SOSTENIBLE, 2007) - ver Ministerio de Planificación (2010b, p.116; 2010c, p.118 [PEDL, Fase III]). En esta misma línea de adopciones glocalizadas, para idéntico Eje estratégico, las municipalidades de Fase IV "adoptan premeditadamente" (ver Misión Lahisí, p. 54; General Belgrano, p. 52, y Villafañe, p. 57) los Objetivos del Milenio establecidos por el PNUD que buscan asegurar un medio ambiente sostenible bajo rótulos como Municipio Ecológico - ver en Ministerio de Planificación (2010d, p. 52 [PEDL, Fase IV]).

Como se observa, la dinámica glocalizada adoptada acríticamente, sigue objetivos definidos en realidades territoriales urbanas foráneas (europeas), que distan en tener alguna similitud con los ámbitos rurales subtropicales de Formosa. $\mathrm{O}$ bien, se traduce en la afiliación premeditada a objetivos de programas multilaterales, como el PNUD, de muy difícil cumplimiento para territorios periféricos, a los que se les transfieren la responsabilidad de ser forjadores por si solos del desarrollo sustentable local.

Finalmente, resulta evidente que las experiencias de los PEDL desconocen las tramas de poder e intereses que acompañan a las estrategias de los actores y a la dialéctica espacial del capitalismo, dando por sentado que, si se sigue la buena praxis de planificaciones estratégicas, se iniciará el camino protagónico, autónomo de inserción a la competitividad global. Así se subraya en el documento PEDL, Fase V de Pozo de Maza:

La decisión de desarrollarse no viene del exterior. Este proceso corresponde a la propia localidad y no puede imponerse. Precisamente, la capacidad de una comunidad de asumir el reto del desarrollo, mediante sus recursos, energías y sinergias constituye su fuerza endógena. (MINISTERIO DE PLANIFICACIÓN, 2012b, p. 33) ${ }^{31}$

La gobernanza del nuevo regionalismo y la territorialización en Herradura

En el marco del proceso de propagación del nuevo regionalismo en la provincia de Formosa, ponemos foco ahora en el caso de la Localidad de Herradura.

31. El concepto de sinergia para el desarrollo local endógeno ha sido trabajado por Sergio Boisier, uno de los actores más influyentes del NOR en América Latina. 
En el año 2002, la gobernación de Gildo Insfrán había definido a la actividad turística como uno de los ejes para el crecimiento económico provincial, para ello, creó la Dirección de Turismo. En el año 2004 se transformará en Ministerio. ${ }^{32}$

Desde la flamante cartera ministerial, Formosa va a alinearse al Plan Federal Estratégico de Turismo Sustentable (PFETS) ingresando su perfil turístico con cuatro circuitos ${ }^{33}$, que serán diseñados con el apoyo del Consejo Federal de Inversiones (CFI) y la Asociación Argentina de Marketing (AAM) para una provincia que no formaba parte de las guías turísticas de la Argentina. Así la AAM, se encarga de posicionar la marca Formosa el Imperio del Verde dentro la actividad turística del país, promocionando junto al Ministerio, las fiestas y festivales organizados en los circuitos definidos para la provincia. Se busca, además, avanzar en lograr un Plan Estratégico de Turismo Sustentable (PETS) para la provincia ${ }^{34}$, con apoyo del Banco Mundial (BM) y el Banco interamericano de Desarrollo (BID), (TORRES FERNÁNDEZ, 2008, p.13), aunque en los hechos, esta incursión por la planificación estratégica se concretiza recién en el 2013 con apoyo del CFI.

No obstante, el frenesí de las decisiones políticas en búsqueda de convertir a Formosa, en una nueva marca y en un nuevo destino en el calendario turístico de la Argentina, llevará al PEP a recrear la idea de construir y hacer posible con la comunidad como se propone desde el NR, la visión del PET: "Una Formosa agrícola, ganadera, forestal, hidrocarburífera, industrial y turística que agrega valor a las materias primas en las regiones donde éstas se producen” (MINISTERIO DEL INTERIOR, 2008, p. 50).

Con esta visualización escalar regional-local y en medio de un mapa provincial, que como se ha apreciado a lo largo de este apartado, ya estaba dominado y expandido de dispositivos institucionales que siguen la lógica fragmentaria del NR, en el año 2010 se decide avanzar sobre el territorio de Herradura como destino turístico.

Así, a través del Decreto Municipal 471/10 de dicha localidad, se declara de interés municipal el lanzamiento del Plan Estratégico de Desarrollo Turístico

32. Se concretiza su estructura y competencia ministerial a través de la Ley provincial $\mathrm{N}^{\circ} 1578$. En 2005 se sanciona la Ley Provincial de Promoción y Fomento al Turismo $N^{\circ} 1484$.

33. Estos Circuitos son: Oeste: bañado La Estrella y Laguna Yema; Este: ciudad de Formosa y alrededores; Norte: Parque Nacional Pilcomayo, Paí Curuzú; Sur: Herradura; Misión Laishí. Estos circuitos fueron promovidos propiciando en esos territorios, la organización de fiestas y festivales. Al respecto, Herradura se convierte en sede del Festival Nacional de la Corvina.

34. Con la asistencia del CFI, se publica el plan en el año 2013. Allí se plantean siete proyectos motores y un listado de 30 proyectos complementarios, entre los cuales figura Herradura (CONCEJO FEDERAL DE INVERSIONES, 2013a, p. 46-87). 
Sustentable de la Micro región de Herradura y su Área de Influencia (PEDTSHyAI), ${ }^{35}$ enmarcado en los PEDL y bajo la consigna: "Herradura Municipio turístico sustentable, para las poblaciones presentes, hallando el camino a las generaciones futuras”. De esta manera, con apoyo financiero internacional ${ }^{36} \mathrm{y}$ con antelación al proceso de planificación y construcción colectiva, se predetermina el eje y destino económico no solo de la localidad y su pueblo, sino también de su espacio geográfico de influencia.

Bajo el manto de estas definiciones impulsadas por arreglos escalares verticalizantes, Herradura se presenta en la geografía de la provincia de Formosa, ubicada en el Departamento Laishí al sureste provincial. Integra, además, la Región Litoral Sur en la nueva territorialización regional. Y se encuentra, a unos 40 kilómetros de distancia de la ciudad de Formosa, capital.

\begin{tabular}{|c|c|c|c|c|c|c|c|}
\hline $\begin{array}{c}\text { Años } \\
\text { Censales }\end{array}$ & $\begin{array}{c}\text { Población total } \\
\text { de la ciudad } \\
\text { de Formosa, } \\
\text { Capital }\end{array}$ & $\begin{array}{c}\text { Población } \\
\text { total del } \\
\text { departamento } \\
\text { Laishí }\end{array}$ & $\begin{array}{c}\text { Población } \\
\text { total de } \\
\text { Herradura }\end{array}$ & $\begin{array}{c}\text { Variación } \\
\text { absoluta }\end{array}$ & $\begin{array}{c}\text { Variación } \\
\text { relativa }\end{array}$ & $\begin{array}{c}\text { Participación } \\
\text { relativa en el } \\
\text { departamento } \\
\text { Laishí (\%) } \\
\text { relativa en } \\
\text { el total de } \\
\text { la población } \\
\text { provincial de } \\
\text { Formosa (\%) }\end{array}$ \\
\hline 1991 & 147.636 & 13.581 & 1.533 & - & - & 11,28 & 0,38 \\
\hline 2001 & 198.074 & 16.227 & 2.333 & 800 & 52,18 & 14,37 & 0,47 \\
\hline 2010 & 222.218 & 17.063 & 2.660 & 327 & 14,02 & 15,58 & 0,50 \\
\hline
\end{tabular}

Cuadro 2. Evolución de la población de Herradura por años censales 1991, 2001 y 2010 Fuente: elaboración propia en base a los Censos de Población y Vivienda (1991; 2001; 2010).

Como se aprecia en el Cuadro 2, la población de Herradura es pequeña en comparación con la población total del Departamento Laishí, y de la ciudad de Formosa Capital, principal centro urbano de la provincia. Si bien su participación relativa en el Departamento es levemente creciente. Su participación relativa en el total de la población de la provincia no logra superar el 1\% a lo largo de los tres últimos Censos. Así, su desenvolvimiento demográfico evolutivo, indica una variación absoluta decreciente en el volumen poblacional, al igual que su variación relativa, evidenciando un proceso de pérdida de población.

De manera complementaria a este ciclo demográfico, se seleccionaron un conjunto de indicadores socioterritoriales como los planteados del Cuadro 3,

35. El Área es identificada por sus ancestros, como "El Camino del Agua”. Un espacio conformado por riachos y lagunas, declarado por la UNESCO en 2001 como Reserva de Biosfera y abarcativa de la localidad de Misión Laishí (MINISTERIO DE PLANIFICACIÓN, 2012a, p.17 [PEDTSHyAI]).

36. El Plan aludido, recibió el apoyo del Programa Multisectorial de Inversión III, préstamo del Banco Interamericano de Desarrollo (BID) 1896 OC-AR. (PEDTSHyAI, 2012a, p.3) (MINISTERIO DE PLANIFICACIÓN, 2012a, p.3 [PEDTSHyAI]). 
referidas a la calidad de las viviendas, dotaciones de equipamiento en de los hogares y propiedad de la tierra.

\begin{tabular}{|l|c|}
\hline Indicadores Socioterritoriales del año 2010 & \% \\
\hline Indicadores Socioterritoriales del año 2010 & $\%$ \\
\hline Viviendas irrecuperables (precarias) & 6,94 \\
\hline Viviendas recuperables (deficitarias) & 57,53 \\
\hline Hogares sin cloacas & 97,41 \\
\hline Hogares sin electricidad & 20,12 \\
\hline Hogares sin gas & 100 \\
\hline Propiedades con tenencia irregular & 44,39 \\
\hline Propiedades con títulos & 50,51 \\
\hline Propiedades Libres & 5,10 \\
\hline
\end{tabular}

Cuadro 3. Indicadores Socioterritoriales de Herradura

Fuente: elaboración propia en base a los datos del Censo de Población y Vivienda (2010) y Ministerio de Planificación (2012a [PEDTSHyAI]).

Surgen del Cuadro 3 las limitaciones estructurales socioterritoriales, especialmente en las calidades de las viviendas, las que sumadas entre deficitarias y precarias, superan más del 60\%. Respecto de los equipamientos básicos en los hogares, surgen déficits importantes como los de desagües cloacales (97,41\%), gas (100\%) y electricidad (20,12\%). Según datos surgidos del Ministerio de Planificación (2012a, p.135 [PEDTSHyAI]), para el 2010: "el sistema de redes de provisión de agua incluye [...] a la planta urbana más consolidada, tiene una cobertura del $60 \%$. En el resto del área rural-urbana el abastecimiento de agua se realiza mediante sistema de pozo". Respecto del área rural, el 97\% de su superficie es destinada a la producción ganadera (Idem, 2012, p. 177).

Estas condiciones demográficas y socioterritoriales configuran a Herradura en un territorio rural urbanizado, según el Ministerio de Planificación (2012a, p. 144 [PEDTSHyAI]), que se ve atravesada por un cuadro complejo de propiedad de la tierra. Al respecto, si bien un poco más del 50\% de las propiedades poseen título, entre propiedades con tenencia irregular (ocupantes de hecho) y las tierras libres, rondan casi el mismo porcentaje que los primeros $49,49 \%$.

Este cuadro complejo de propiedad de la tierra se encuentra sujeto a la presión de actividades de explotación turística, que penetran el espacio territorial de modo creciente como se observa en el Cuadro 4. 


\begin{tabular}{|l|l|}
\hline \multicolumn{2}{|c|}{ Actividades de explotación turística } \\
\hline Número de Cabañas: $\mathbf{2 0 1 3 - 2 0 2 0}$ \\
\hline Cabaña La Florencia & Número de Cabañas: 10 \\
\hline Cabaña de La Laguna & Cabaña La Florencia \\
\hline Número de Posadas: 1 & Cabaña de La Laguna \\
\hline Posada Kuarajy Ko'e & Cabaña El Cortijo \\
\hline Número de Camping: 1 & Cabaña Los Zorzales - Estancia \\
\hline \multirow{2}{*}{ Camping Chuqui Cué } & Cabaña Gran Capitán \\
\hline Número de Estancias: $\mathbf{1}$ & Cabaña Amanecer en el Bosque \\
\hline \multirow{2}{*}{ Estancia Yaciretá } & Cabaña La Madrina \\
\hline \multirow{5}{*}{} & Cabaña Miramonte \\
\hline & Cabaña Lo de Mis Viejos \\
\cline { 2 - 3 } & Cabaña Picasso \\
\cline { 2 - 3 } & Número de Camping: 6 \\
\cline { 2 - 3 } & Número de Casas Quintas: 10 \\
\cline { 2 - 3 } & Número de Casa y Departamentos: 4 \\
\hline
\end{tabular}

Cuadro 4. Actividades de explotación turística de capitales privados en Herradura en 2010, y 2013-2020

Fuente: elaboración propia en base a datos del Ministerio de Planificación (2012a, p.260 [PEDTSHyAI]) y de la Dirección de Planificación de Desarrollo Local, Guía Turística Herradura (2020).

Llamamos aquí actividades de explotación turística, a la realización de actividades lucrativas que ofrecen a los turistas espacios de alojamiento y esparcimiento, que se encuentran por fuera de las actividades comerciales y de otros servicios (gastronomía, paseos, excursiones, pesca). Se evidencia en el Cuadro 4 que el total de las explotaciones instaladas al momento de la realización del PEDTSHyAI constituían solo cinco actividades, mientras que, entre los años 2013-202037, la penetración del capital que explota estas actividades se multiplica por seis, elevándose a treinta el total de estas actividades económicas.

Una característica del avance de los nuevos ingresos de capitales privados que se van instalando en el territorio, es la inexistencia de marcos regulativos de parte del Estado Municipal, estableciendo códigos o estándares urbanísticos que impidan dañar los ecosistemas y darle el sentido de sustentabilidad a la explotación que se radica, según se argumenta en el Ministerio de Planificación (2012a, p. 20 [PEDTSHyAI]) existen controles municipales que indiquen si los

37. Si bien el período se extiende más allá del neo-desarrollismo, se destaca el cambio de tendencia y avance en la presión sobre el territorio, con el crecimiento significativo de explotaciones turísticas. A manera de ejemplo se enumera el aumento en el número de Cabañas. 
terrenos donde se van instalando son inundables ${ }^{38}$. Así lo cuenta Ricardo, un inversor privado que compró una parcela para la instalación de nuevas Cabañas:

\begin{abstract}
El municipio no te pide ni exige nada, todo es bastante precario, [...] Cuando compré la parcela, no me pidieron nada y los servicios que pagas por agua y electricidad son muy baratos, por lo menos en este tiempo en que me estoy instalando [...] no me dijeron si el lugar era inundable o no, lo averigüe yo por iniciativa propia, [...] tampoco el municipio me pidió el pago de ningún canon, impuesto, o tasa por mi emprendimiento que estoy haciendo. (Entrevista a Ricardo, inversor en Cabañas, abril, 2020).
\end{abstract}

Respecto de los capitales cabañeros ya asentados en Herradura desde el año 2010 en adelante, es posible destacar, varias características. Por una parte, el origen de sus propietarios, el número de empleados y sus condiciones de formalidad contractual, y los proveedores que utilizan a la hora de la prestación de los servicios. Así lo cuentan Patricia y Ezequiel integrantes de la Asociación de Cabañeros de Herradura (ACH):

Mi emprendimiento comenzó con cinco cabañas en el 2010 y nos financiamos con fondos de CFI articulados a través del gobierno provincial, luego crecimos y hacia el 2015 obtuvimos otro préstamo de la misma entidad para construir cinco más, a las que agregamos 3 piscinas [...]; el 99\% de los cabañeros instalados son de Formosa, a excepción de uno que es un fideicomiso de la provincia de Mendoza, [...]; las prestaciones de los servicios aun no tienen una conexión con los productores locales de Herradura, toda nuestra proveeduría para atender a nuestros clientes proviene de Formosa Capital, [...]; la atención la hacemos con 2 empleados los fines de semana, pero en vacaciones de invierno y especialmente en verano donde se llena nuestra capacidad instalada contamos con 4 empleados de los cuales sólo pudimos formalizar a uno. (Entrevista a Patricia, integrante propietaria de la ACH, abril, 2020).

Nuestras cabañas han tenido un financiamiento con un 50\% de capital propio y el otro 50\%, lo consiguió mi padre [...] con funcionarios del gobierno provincial, eran unos fondos subsidiados que estaban atados a que sí o sí debíamos incorporar una actividad ecológica. Por eso, lo de la extracción de miel del monte [...]; todos los que estamos en la actividad cabañera somos formoseños capitalinos. Prestamos nuestro servicio con 4 cabañas, pero como es zona inundable, las construimos sobre uno pilares [...] para este tipo de instalación el Municipio no nos dio ninguna pauta a cumplimentar. Trabajan en el

38. Al respecto en el Plan aludido, se enuncia un grupo de obras que prometen erradicar un problema estructural de inundabilidad de Herradura. (MINISTERIO DE PLANIFICACIÓN, 2012a, p. 247 [PEDTSHyAI]). 
lugar dos personas y en temporada alta 4, de los cuales dos están formalizados, [...] respecto de la proveeduría no conseguimos articular nada con el Municipio, y tampoco con los productores locales, a tal punto, por ejemplo, que como el predio no cuenta con agua corriente, debemos traer en camiones desde Formosa capital. (Entrevista a Ezequiel, integrante de la ACH y Gerente de Cabañas, abril, 2020).

Por último, se revela cuál es el origen de la demanda turística que habitualmente asiste a la localidad de Herradura. Según las experiencias acumuladas de Patricia y Ezequiel integrantes de la ACH, estos plantean:

La demanda es bien estacional. Funciona bien el negocio en vacaciones de invierno y con plena ocupación en verano. Luego de estas temporadas, se mueve muy poco y solo los fines de semana. El 99\% de nuestros clientes son de Formosa capital, es muy raro que haya alguno de nuestro interior provincial o de otras provincias. (Entrevista a Patricia, integrante propietaria de la ACH, abril, 2020).

A esta mirada agrega Ezequiel que:

La demanda está cubierta en un 100\% por gente que viene de Formosa Capital, pero es muy estacional. En verano es cuando mejor nos va. Esto es porque nuestro público son esencialmente empleados públicos cuyos niveles de ingresos no son muy altos y algunos aprovechan solo los fines de semana. (Entrevista a Ezequiel, integrante de la ACH y Gerente de Cabañas, abril, 2020).

\section{Conclusiones}

Como se ha analizado, la experiencia neo-desarrollista finalmente no logró desterrar de raíz el proceso de neoliberalización. En tal sentido, a escala sub-nacional el Estado formoseño impuso a lo largo de ese período un conjunto de dispositivos fragmentantes, basados en los lineamientos de un "nuevo regionalismo" que convergió, a una "nueva ortodoxia regionalista o pensamiento único localista".

Esa dinamización de políticas públicas, que combinaron procesos de re-escalonamientos y territorialización generó el remodelado de ordenamiento territorial de la provincia a través de un proceso de "regionalización” que sirvió de base para la propagación de los lineamientos aludidos. En ese entramado configurado se renovó y complejizó la ya tradicional desarticulación de la vida económica provincial, dando lugar a nuevas formas institucionales y de mercantilización, que exacerbaron su carácter territorial desigual.

Es que esa nueva ortodoxia implantada no tiene como centralidad al Estado, en consecuencia, cuando entran en funcionamiento a nivel regional/local y se 
acoplan con la estructura productiva territorial, desencadenan nuevas desigualdades espaciales y sociales o bien continúan/persisten, se refuerzan las ya existentes como se observó en el caso Herradura, donde se pudo apreciar además, que dispositivos como los planes estratégicos operan en realidad, como medio de legitimación o acondicionan el territorio a las necesidades de penetración del capital con regulaciones amigables a estos intereses.

El análisis de este caso sugiere a partir de estos elementos hallados la configuración de un patrón regulativo escalar que se extendió en casi todo el territorio formoseño, cuya dinamización institucionalizada, viene a recrear formas de intervención estatal asimilables a la neoliberalización.

Así se ha apreciado que en Herradura, el patrón de gobernanza no emerge para repensar el territorio de una forma colectiva, horizontal y participativa en búsqueda de alcanzar el desarrollo endógeno local, sino para dar continuidad a formas de producción existentes o bien para adecuar las condiciones territoriales a los arreglos escalares verticalizantes que predeterminan el eje y destino económico de la localidad y del espacio geográfico de influencia y median para acomodar las necesidades del capital.

La dinámica operacional del Estado introduce de esta manera, una lógica de co-producción de políticas con los actores regionales/locales público-privados, que imponen un despliegue de los procesos de mercantilización de los recursos naturales, a través de una implicación estatal que facilita y renueva complejos procesos de desarticulación fragmentante, al accionar la dinámica regional/local, dándole continuidad y re-elaboración al proyecto neoliberal.

La raíz de ese patrón regulativo escalar se apoya en un conjunto de inconsistencias y limitaciones que son aceptadas de manera acrítica por los ejecutores de políticas públicas en el territorio. Son ellas:

1. Su concepción de la dinámica del desarrollo, está basada en una visualización simplista, bipolar global-local, que desconsidera las tramas de poder e intereses que acompaña a las estrategias de los actores económicos e institucionales y a la dinámica espacial del capitalismo;

2. El ensamble de las ideas de Redes de Económicas Global-REG y los enfoques regionalistas, no logran problematizar debidamente en la dimensión global, las formas de gobernanza y el poder de los grandes actores transnacionales que las gobiernan, en consecuencia, la inserción de las escalas mesoregionales/locales en las REG, para obtener mejoras en dichas redes, se remite solo a vincularlas con la calidad del entorno territorial; 
3. Debido a estas limitaciones, cuando se vinculan con los espacios institucionales, resulta funcional a la lógica de neoliberalización fragmentadora que se impulsan desde las redes políticas globales, lideradas por los organismos financieros y no financieros internacionales, en concordancia con el mantenimiento de las estructuras de poder desigualadoras y subordinantes que contienen las redes económicas globales, controladas por las grandes firmas emplazadas fundamentalmente en el centro;

4. Desde esta mirada de nuevo regionalismo y sus manuales de las buenas prácticas se impone el sendero que se cree, conducirá a Formosa y sus localidades al desarrollo económico, propulsando un conjunto de dispositivos fragmentarios (como programas de competitividad, conformación de clusters, planes estratégicos de desarrollo local, Agencia de desarrollo empresarial, entre otros) en línea con los principios de base participativa y comunitarista de la NOR y con el financiamiento de los organismos internacionales que sustentan esta perspectiva. Esa dinámica fragmentaria es la que opera como patrón regulativo y de acumulación que le da continuidad y persistencia al carácter re-primarizado y subordinado de Formosa a los intereses de la región central del país.

Esas debilidades y limitaciones coadyuvaron a que el antídoto neo-desarrollista contra la neoliberalización agitó las contradicciones en el proyecto político que lideró en la Argentina estas experiencias, y allanó el camino para el ascenso de la restauración neoconservadora y el dominio de los intereses vinculados al gran capital desde el año 2016.

\section{Referencias}

ADRIANI, H. L. Territorio y desarrollo en la Argentina posconvertibilidad. En: FÉLIZ, M.; LÓPEZ, E.; GARCÍA M. (coords.). Desarmando el modelo. Desarrollo, conflicto y cambio social tras una década de neodesarrollismo. Buenos Aires: El Colectivo, (Ensayo e Investigación), 2016, p. 261-276.

ALGRANATI, C.; SEOANE, J.; TADDEI, E. Realidades y desafíos políticos de Nuestra América. Una década de luchas sociales y cambios políticos en América Latina. Revista América Latina, Santiago de Chile, p. 25-47, mayo, 2011.

AMIN, A.; ROBINS, K. The re-emergence of regional economies? The Mythical Geography of Flexible Accumulation. Society and Space, v. 8, p. 7-34, mar. 1990.

BECATTINI, G. Le district industriel. Espaces et sociétés, n. 66, p.143-147, sept. 1992.

BRANDÃO, C. Territorio y desenvolvimiento. As múltiplas escalas entre o local e o global. Campinas: Editora Unicamp, 2007. 
CAO, H.; VACA, J. Desarrollo Regional en la Argentina: la centenaria vigencia del patrón de asimetría regional. Santiago de Chile. EURE, v. XXXII, nº 95, p. 95-111, mayo, 2006.

CETRÁNGOLO, O.; GATTO, F. Dinámica productiva provincial a fines de los años noventa. Buenos Aires. CEPAL. Serie Estudios y Perspectivas, v. 14, p. 5 -75, marzo, 2003.

CONCEJO FEDERAL DE INVERSIONES. Elaboración de planes estratégicos de desarrollo local provincia de Formosa. 2007a. Disponible en http://biblioteca.cfi.org.ar/documento/elaboracion-de-planes-estrategicos-de-desarrollo-local-provincia-de-formosa/. Acceso en: 11 de mayo 2015.

. Planes Estratégicos de Desarrollo Local. 2007b. Disponible en: https://www.formosa.gob.ar/modulos/planificacion/templates/files/PEDL_Formosa_Caratula_Indice.pdf. Acceso en: 11 de mayo de 2015.

. Planes estratégicos de desarrollo local provincia de Formosa Fase IV de la Provincia de Formosa. 2007c. Disponible en: http://biblioteca.cfi.org.ar/documento/planes-estrategicos-de-desarrollo-local-fase-iv-provincia-de-formosa. Acceso en: 11 de mayo de 2015.

. Elaboración de Planes estratégicos de desarrollo local de la Provincia de Formosa. 2011. Disponible en: http://biblioteca.cfi.org.ar/documento/elaboracion-de-planes-estrategicos-de-desarrollo-local-provincia-de-formosa-2. Acceso en: 11 de mayo de 2015.

. Plan Estratégico de Turismo Sustentable de la Provincia de Formosa. Documento Final. 2013a. Disponible en: http://biblioteca.cfi.org.ar/wp-content/uploads/sites/2/2013/01/4976o.pdf. Acceso en: 11 de mayo de 2015.

. Planes estratégicos de desarrollo local provincia de Formosa Fase VII de la Provincia de Formosa. 2013b. Disponible en http://biblioteca.cfi.org.ar/documento/planes-estrategicos-de-desarrollo-local-fase-vii-provincia-de-formosa. Acceso en: 11 de mayo de 2015.

COOKE, P. Regional Innovation Systems: Competitive Regulation in the New Europe. Geoforum, vol. 23, n 3, p. 365-382, 1992.

DIRECCIÓN DE PLANIFICACIÓN DE DESARROLLO LOCAL. Guía Turística Herradura. 2020. Disponible en: https://archivos.formosa.gob.ar/media/uploads/desarrollo_local_det/desarrollo_1582030840.pdf. Acceso en: 12 de abril 2020.

FÉLIZ, M. El tiempo que nos tocó. Dependencia, crisis y luchas sociales en la Argentina reciente. Buenos Aires: El Colectivo, 2019.

FERNÁNDEZ, V. R.; AMIN, A.; VIGIL J I. Repensando el Desarrollo Regional. Contribuciones globales para una estrategia latinoamericana. Buenos Aires: Miño y Dávila, 2008.

FERNÁNDEZ, V. R.; CARDOZO L. G. Nueva Estatidad bajo la Re-emergencia Regional. La reelaboración del proyecto neoliberal y sus alteraciones en la periferia. Revista Brasileira de Estudos Urbanos e Regionais, v. 14, nº 2, p. 11-33, nov., 2012.

FERNÁNDEZ, V. R. Desde el laboratorio neo-desarrollista a la resurgencia neoliberal. Una revisión creativa del ‘doble movimiento’ polanyiano en América Latina. Revista Estado y Políticas Públicas, 7, p. 21-47, 2016.

FERNÁNDEZ, V. R.; COMBA, D. Sistemas Regionales de Innovación en la periferia: una perspectiva crítica. Redes, v. 22, nº1, p. 376-401, abr. 2017. 
GARCÍA, A. Auge y caída de la planificación regional en Argentina: entre la búsqueda de una autonomía enraizada y el escenario económico del capitalismo periférico. Cuadernos de Geografía: Revista Colombiana de Geografía, v. 27, n¹, p.180-94, 2016.

GIULIANO, E. F. Sociedades Periféricas y Multiterritorios. Análisis de la estructura social de Formosa en el ciclo 1980-2002. Buenos Aires: La Colmena, 2015.

Los cambios a nivel funcional y espacial del Estado y las Estructura productiva territorial formoseña. Análisis del ciclo 1991 - 2012. 420 f. Tesis (Doctorado en Ciencias Sociales). Facultad de Ciencias Sociales, Universidad de Buenos Aires, Buenos Aires, 2019.

GORENSTEIN, S (org.). ¿Crecimiento o Desarrollo? El ciclo reciente en el norte argentino. Buenos Aires: Miño y Dávila, 2012.

HADJIMICHALIS, C. SMEs, entrepeneurialism, and local/regional development. En: PIKE, A.; RODRÍGUEZ-POSSE, A. TOMANEY, J. (eds.) Handbook of local and regional development. London: Routledge, p. 381-93, 2011.

HARVEY, D. El nuevo imperialismo: acumulación por desposesión. En: PANITCH, L.; LEYS, C. (eds.) Socialist Register 2004. El nuevo desafío imperial. Buenos Aires: CLACSO, p. 99-130, 2005 .

HONORABLE CÁMARA DE DIPUTADOS DE LA PROVINCIA DE FORMOSA. p. 12, 2003 a. Constitución de la Provincia de Formosa del año 2003. Disponible en: https://www.legislaturaformosa.gov.ar/biblioteca. Acceso en: 20 de abril de 2015.

. p. 25-36, 2003b. Constitución de la Provincia de Formosa del año 2003. Disponible en: https://www.legislaturaformosa.gov.ar/biblioteca. Acceso en: 20 de abril de 2015.

JESSOP, R. El futuro del Estado Capitalista. Madrid: De la Catarata, 2008.

KATZ, C. Anatomía del kirchnerismo. Rebelión. 2013. Disponible en: https://fisyp.org.ar/wp-content/uploads/media/uploads/anatomia.pdf. Acceso en: 25 de septiembre de 2020.

LIPIETZ, A. El posfordismo y sus espacios. Las relaciones capital-trabajo en el mundo. En: PIETTE-CONICET. Series Seminarios de Investigación Intensivos. Documento de Trabajo $\mathrm{N}^{\circ}$ 4, Facultad de Ciencias Económicas de la Universidad de Buenos Aires, p. 1-52,1994.

MANZANAL, M. Neoliberalismo y territorio en la Argentina de fin de siglo. Economía Sociedad y Territorio, vol. 2, $\mathrm{n}^{\circ}$ 7, p 433-58, enero, 2000.

MINISTERIO DEL INTERIOR, Planes-Provincia. Plan Estratégico Territorial Formosa 2015: El Plan de inversiones que conduce la visión de provincia en el largo plazo. 2008. Disponible en: https://www.mininterior.gov.ar/planificacion/pdf/planes-prov/ FORMOSA/Plan-Estrategico-Formosa-2015.pdf. Acceso en: 11 de mayo de 2015.

MINISTERIO DE PLANIFICACIÓN. Inversión, Obras y Servicios Públicos Subsecretaría de Planificación de la Inversión Pública. p. 1-7. 2006. Disponibles en: https://fsaynea.files. wordpress.com/2011/04/regionalizacion-de-la-provincia-de-formosa-doc1.pdf. Acceso en: 15 de abril 2014.

Planes Estratégicos de Desarrollo Local (PEDL), Fase II, 2007. Disponible en: https:// www.formosa.gob.ar/planificacion/desarrollolocal. Acceso en: 10 de abril de 2016. 
MINISTERIO DE PLANIFICACIÓN. Planes Estratégicos de Desarrollo Local (PEDL), Fase III, 2010a. Disponible en: https://www.formosa.gob.ar/planificacion/desarrollolocal. Acceso en: 10 de abril de 2016.

Planes Estratégicos de Desarrollo Local (PEDL), Fase III de Tres Lagunas, 2010b. Disponible en: https://archivos.formosa.gob.ar/media/uploads/desarrollo_local_det/desarrollo_1582035912.pdf. Acceso en: 10 de abril de 2016.

. Planes Estratégicos de Desarrollo Local (PEDL), Fase III de General Güemes, 2010c. Disponible en: https://archivos.formosa.gob.ar/media/uploads/desarrollo_local_det/desarrollo_1582035997.pdf. Acceso en: 10 de abril de 2016.

Planes Estratégicos de Desarrollo Local (PEDL), Fase IV Misión Laishí, 2010d. Disponible en: https://archivos.formosa.gob.ar/media/uploads/desarrollo_local_det/desarrollo_1582035320.pdf. Acceso en: 10 de abril de 2016.

. Inversión, Obras y Servicios Públicos Subsecretaría de Planificación de la Inversión Pública. p. 1-21. 2011. Disponible en: https://fsaynea.files.wordpress.com/2011/o4/regionalizacion.pdf. Acceso en: 15 de abril 2014.

Planes Estratégicos de Desarrollo Turístico Sustentable de la Microrregión de Herradura y su Área de Influencia (PEDTSHyAI), 2012a. Disponible en: https://archivos. formosa.gob.ar/media/uploads/desarrollo_local_det/desarrollo_1582030787.pdf. Acceso en: 10 de abril de 2016.

Planes Estratégicos de Desarrollo Local (PEDL), Fase V Pozo de Maza, 2012b. Disponible en: https://archivos.formosa.gob.ar/media/uploads/desarrollo_local_det/desarrollo_1582035763.pdf. Acceso en: 10 de abril de 2016.

Planes Estratégicos de Desarrollo Local (PEDL), Fase VII, 2013. Disponible en: https://www.formosa.gob.ar/planificacion/desarrollolocal. Acceso en: 10 de abril de 2016.

PECK, J; TICKELL, A. Searching for a new institucional fix: the after-fordist crisis and the global-local disorder. En: AMIN, A. (Ed.). Post-Fordism: a reader. Malden: Blackwell, 1994. p. 280-315.

Making global rules. Globalization or neoliberalization?, En: PECK, J; WAI-CHUNG YOUNG, H. (eds.) Making the global economy. London: Sage, 2003, p. 167-81.

PECK, J. Economías y políticas de escala: políticas rápidas, relaciones interescalares y workfare neoliberal. En: FERNÁNDEZ, V.; BRANDÃO, C. (orgs). Escalas y políticas del desarrollo regional. Desafíos para América Latina. Buenos Aires: Miño y Dávila, 2010. p. 92-116.

Neoliberalismo y Crisis Actual. Documentos y Aportes en Administración Pública y Gestion Estata, 12, n 19, p. 7-27, 2012.

PINASSI, M. O.; ADOUE, S. B. Primer prólogo. En: FÉLIZ, M. El tiempo que nos tocó. Dependencia, crisis y luchas sociales en la Argentina reciente. Buenos Aires: El Colectivo, 2019, p. 11-17.

PORTER, M. Clusters and the new economics of competition. Harvard Business Review, nov.-dez. 1998. Disponible en: http://www.rimisp.org/wp-content/uploads/2012/07/31_rimisp_Cardumen.pdf. Acceso en: 31 de Julio de 2012. 
REDE DE REDES DE DESARROLLO LOCAL SOSTENIBLE. Libro verde del medio ambiente urbano. 2007. Disponible en: http://www.bcnecologia.net/sites/default/files/publicaciones/docs/libro_verde_medio_ambiente_urbano_partes_12_y_3_salida.pdf. Acceso en: 14 de mayo de 2014.

SALVIA, S. El modo de acumulación en la Argentina reciente. Del neoliberalismo a la Posconvertibilidad. En: BONNET, A.; PIVA, A. (comps.) El modo de acumulación en la Argentina contemporánea. Buenos Aires: Imago Mundi, 2019, p. 51-70.

SCHORR, M.; FERREIRA, E.; GORENSTEIN, S. Complejos Productivos con encadenamientos industriales en el norte argentino: algodón, azúcar y foresto-industria. En: GORENSTEIN, S. (org.) ¿Crecimiento o Desarrollo? El ciclo reciente en el norte argentino. Buenos Aires: Miño y Dávila, 2012, p. 55-82.

SMITH, N. Scale Bending. En: SHEPPARD, E.; MC MASTER, R. (Eds.). Scale y Geographic Inquiry: Nature, Society and Method. Londres: Blackwell, 2003, p. 192-212.

SWYNGEDOUW, E. ¿Globalización o glocalización? Redes, territorios y reescalonamiento. En: FERNÁNDEZ, V. R.; BRANDÃO, C. Escalas y políticas del desarrollo regional. Desafíos para América Latina. Buenos Aires: Miño y Dávila, 2010, p.47-70.

TORRES FERNÁNDEZ, P. Redefiniendo alteridades. Políticas provinciales de turismo étnico en Chaco y Formosa. En: CONGRESO ARGENTINO DE ANTROPOLOGÍA SOCIAL, 9, 2008, Anais do IX Congreso Argentino de Antropología Social. Posadas: Facultad de Humanidades y Ciencias Sociales, Universidad Nacional de Misiones, 2008. 


\section{Ernesto Fabián Giuliano}

Es Licenciado en Economía por la Universidad Nacional de Córdoba, Córdoba, Argentina; Magister en Gestión Territorial y Desarrollo por la Universidad Nacional de Rosario, Santa Fe, Argentina; Doctor en Ciencias Sociales por la Universidad de Buenos Aries, Buenos Aires, Argentina y Docente e investigador de la Facultad de Administración Economía y Negocios (FAEN), Universidad Nacional de Formosa (UnaF), Formosa, Argentina.

Email: giulianoernestoo2@gmail.com

ORCID: 0000-0002-9699-8148

Sumisión: 30 de noviembre de 2020.

Aprobación: 3 de junio de 2021.

Cómo citar: GIULIANO, E. F. Neo-desarrollismo y nuevo regionalismo en Formosa (nordeste-argentino): operaciones estatales y reelaboración neoliberal. Revista brasileira de estudos urbanos e regionais. V.23, E202116, 2021. DOI 10.22296/2317-1529.rbeur.202116

Artigo licenciado sob Licença Creative Commons CC BY 4.0.

https://creativecommons.org/licenses/by/4.o/ 